\title{
PENYULUHAN KEWIRAUSAHAAN DAN PEMBERDAYAAN SISWA YATIM PIATU DI CIPUTAT TANGERANG SELATAN BANTEN
}

\author{
Lies Sunarmintyastuti ${ }^{1}$, Hugo Aries Suprapto ${ }^{2}$, Loecita Sandiar $^{3}$, Ari Wahyu Leksono ${ }^{4}$, \\ Sigit Widiyarto 5 \\ ${ }^{1}$ Program Studi Teknik Informatika, Universitas Indraprasta PGRI Jakarta \\ ${ }^{2}$ Program Studi Teknik Indusrtri, Universitas Indraprasta PGRI Jakarta \\ ${ }^{3,4,5}$ Program Studi Pendidikan Ekonomi, Universitas Indraprasta PGRI Jakarta \\ ${ }^{5}$ sigit.widiyanto372@gmail.com
}

\begin{abstract}
Entrepreneurship is a field that is still less attractive to adolescents. But the efforts that have been carried out by the government and the private sector have been many. It still needs the support of many parties, including community service activities carried out in Islamic boarding schools. The purpose of community service activities is to instill entrepreneurial values early on in students. It is hoped that in the future students will become reliable and professional entrepreneurs. This activity was carried out from April to July 2020. The method used was the method of practice and providing counseling and monitoring of implementation. Students who participated were orphaned students at the Ciputat Arrahman Foundation Tangerang, totaling 23 students. The results of this activity indicate that students have been able to make several souvenir models from paper. The target results for each group are 100\%, $80 \%$ and $70 \%$. Students are given the opportunity to deliver the results of their products in the pesantren environment, some are also sold in the cooperative and to the surrounding community. Community response to the results of the students good and positive
\end{abstract}

Keywords: Entrepreneurship, Empowerment, Orphans

\begin{abstract}
Abstrak:Kewirausahaan merupakan bidang yang masih kurang diminati oleh kalangan remaja. Namun upaya yang sudah dilaksanakan oleh pemerintah dan pihak swasta sudah banyak. Masih perlu dukungan banyak pihak,termasuk kegiatan pengabdian masyarakadilakukan di pondok pesantren. Tujuan kegiatan pengabdian kepada masyarakat ini untuk menanamkan nilai - nilai kewirausahaan sejak dini pada siswa. Diharapkan pada waktu yang akan datang para siswa menjadi wirausahawan yang handal dan professional. Kegiatan ini dilaksanakan dari bulan April sampai dengan Juli 2020. Metode yang digunakan adalah metode praktek dan pemberian penyuluhan serta monitoring pelaksanaan. Siswa yang ikut adalah siswa yatim piatu pada yayasan Arrahman Ciputat Tangerang, sebanyak 23 siswa. Hasil kegiatan ini menunjukkan bahwa siswa sudah mapu membuat beberapa model souvenir dari kertas. Hasil target masing - masing kelompok sebesar 100\%, $80 \%$ dan 70\%. Siswa diberikan kesempatan untuk meamsarkan hasil produk mereka di dalam lingungan pesantren, sebagian juga dijual dikoperasi dan kepada masyarakat sekitar. Respon masyarakat kepada hasil dari para santriwan baik dan positif.
\end{abstract}

Kata Kunci : Kewirausahaan, Pemberdayaan, siswa Yatim Piatu

\section{Pendahuluan}

Rasio jumlah wirausahawan atau pengusaha di Indonesia saat ini baru mencapai 2 persen dari total penduduk. Idealnya, kata Hal Udisubakti Ciptomulyono, Dekan Fakultas Bisnis dan Manajemen Teknologi ITS (Institut Teknologi Sepuluh November, rasio wirausahawan adalah 4 persen agar bisa mendorong pertumbuhan ekonomi nasional. Di Indonesia rata-rata lulusan SLTA $(61,88 \%)$ mempunyai image dan pandangan lebih baik bekerja di perusahan menjadi karyawan daripada menjadi wirausaha. Pendidikan dapat dimulai dari lingkungan keluarga, masyarakat dan pemerintah. Hal ini sesuai dengan pernyataan Redja Mudyaharjo (2012:11), pendidikan merupakan usaha sadar yang dilakukan oleh keluarga, masyarakat, dan pemerintah, melalui kegiatan bimbingan, pengajaran dan latihan yang berlangsung di sekolah dan di luar sekolah sepanjang hayat, untuk mempersiapkan peserta didik agar dapat memainkan peranan dalam berbagai lingkungan hidup secara tepat di masa yang akan datang. Menurut Suryana $(2014: 2)$ 
Kewirausahaan (entrepreneurship) adalah suatu disiplin ilmu yang akan mempelajari tentang nilai, kemampuan (ability), dan perilaku seseorang dalam menghadapi tantangan hidup dan cara memperoleh peluang dengan berbagai risiko yang mungkin dihadapinya.

Kegiatan sosialisasi penyuluhan pelatihan keterampilan pembuatan souvenir ini adalah untuk membentuk karakter sejak dini kepada santriwati di Yayasan Tahfidzul Qur'an Ar-Rahmani agar selain mereka hafal Qur'an juga memiliki modal ilmu keterampilan agar bisa membuat suatu produk inovasi dari barang-barang bekas. Tujuan yang dilakukan sangat jelas dan bermanfaat bagi santriwati setelah mereka lulus dari yayasan dan memiliki jiwa mandiri entrepreneur. Santriwati selepas dari mengemban ilmu di Yayasan Tahfidzul Qur'an Ar-Rahmani dituntut memiliki kemandirian finansial selepas lulus dari SLTA dan Perguruan Tinggi. Tidak mudah dalam kemandirian finansial tersebut, proses yang tidak mudah, proses yang tidak cepat, diperlukan jiwa kemandirian dari waktu ke waktu.

Sejalan dengan konsep kemandirian sejak dini, diperlukan dorongan kepada santriwati, karena semangat kemauan belajar mereka masih tinggi, dan ide-ide kreatif inovatif dibentuk sedari awal agar konsep kemandirian berwirausaha santriwati menjadi tinggi. Keberhasilan seorang wirausaha untuk mengembangkan bisnisnya tergantung pada kecerdasan, imajinasi, dan kekuatan keinginan individu yang bersangkutan. Sedikit keberuntungan diperlukan, tetapi dapat diargumentasika $\mathrm{n}$ bahwa tidak ada keberuntungan mengubah visi menjadi realita lebih berupa kerja keras, di samping imajinasi dan kemampuan yang mampu merubah karir individu menjadi sukses. (Rachbini, 2001:100).

Pelatihan hal seperti sangat diperlukan oleh para santriwati, karena jiwa dan pengetahuan mereka masih sangat minim, maka pendampingan untuk membentuk karakter menumbuhkan jiwa kemandirian bewirausaha sangat dibutuhkan oleh mereka. Potensi santriawati bisa dibetuk dengan adanya penyuluhan dari tim abdimas. Tak kalah penting kendala lain dari para santriawati adalah kurangnya motivasi. Dalam hal ini kami tim dosen yang merupakan pengajar keilmuan kewirausahaan berusaha membentuk jiwa wirausaha mereka. Alasan kami memilih santriawati di Yayasan Tahfidzul Qur'an Ar-Rahmani adalah karena mereka belum pernah sama sekali mendapatkan pelatihan keterampilan membuat produk. Berdasarkan survei, pengamatan, observasi dan wawancara langsung yang tim abdimas lakukan terhadap santriawati disimpulkan bhawa hampir semua dari 30 santriawati yang ada di Yayasan Tahfidzul Qur'am Ar-Rahmani belum pernah mendapatkan materi kewirausahan, tetapi dilihat dari kematangan usia, kematangan berpikir, kedewasaan kemandirian dan Jiwa sosial masih minim.

Hasil pengamatan dan identifikasi yang tim abimas lakukan menunjukkan bahwa ada permasalahan yang harus ditindaklanjuti oleh tim abdimas, yaitu pertama adalah masih kurangnya/minimnya pengetahuan dalam berwirausaha, yang kedua adalah belum memiliki targer dan rencana sasaran produk yang dibuat, yang ketiga adalah belum memiliki pengetahuan dalam hal target penjualan/promosi pemasaran. Jadi salah sat upaya yang kami lakukan sebagai tim abdimas adalah memebrikan pengetahuan materi kewirausahaan dan yang terpenting yaitu melatih para santriwati memiliki keterampilan dam membuat produk. Hali ini dilakukan karena prospek pembuatan souvenir dari barang-barang bekas sangat baik dan tidak memerlukan modal besar, cukup diperlukan ide kreafi inovatif. Dengan adanya penyuluhan pelatihan keterampilan pembuatan produk ini diharapkan dapat mengasah kemampuan mereka dan 
menjadi lebih semangat dalam berwirausaha, terutama mendapatkan uang saku dan santriwati lebih mandiri terhadap finasial.

Berdasarkan uraian diatas, maka tim abdimas memutuskan untuk memberikan penyuluhan pelatihan keterampilan pembuatan souvenir untuk meningkatkan keterampilan berwirausaha di Yayasan tahfidzul Qur'an Ar-Rahmani di Kampung Sawah, Ciputat, Kota Tangerang Selatan. Dari kegiatan yang bermanfaat ini diharapakan membentuk karakter jiwa berwirausaha generasi muda Indonesia, sehingga mampu membuat mereka lebih mandiri untuk masa depan mereka serta berpikir positif dengan ide, kreatifi inovatif.

\section{Metode}

Pelaksanaan penyuluhan dilakukan di Yayasan Tahfidzul Qur'an yang beralamat di Jl. Al-Ihsan Rt 02/07 Kampung Sawah, Kec. Ciputat, Kab. Tangerang Selatan. Penyuluhan ini di peruntukan bagi santriwati yang sedang menimba ilmu di lingkungan Yayasan tersebut, dengan tahapan sebagai berikut :

1. Melakukan kunjungan ke yayasan tahfidzul Qur'qan Ar-Rahmani, untuk menyampaikan maksud Tim Abdimas ke lokasi. Dan sasaran yang diberikan para santriwati yang sedang menimba ilmu di lingkungan Yayasan tahfudzul Qur'an Ar-Rahmani.

2. Tim abdimas menganalisa kebutuhan mitra, mengumpulkan bahan dan materi yang akan digunakan untuk penyuluhan keterampilan pembuatan souvenir kepada pihak yayasan

3. Pelaksanaan abdimas.

4. Pelatihan diberikan kepada santriwati di lingkungan Yayasan Tahfidzul Qur'an dilokasi yang sudah disiapkan oleh pihak Mitra Abdimas, yaitu di rumah kediaman yang beralamat di Kp. Sawah,
Ciputat, Tangerang Selatan yang juga dijadikan tempat menimba ilmu para santriwati.

5. Pelaporan Kegiatan

6. Melakukan sejumlah analisa terhadap hasil kegiatan dan mengambil kesimpulan untuk dapat dilakukan perbaikan pada kegiatan abdimas selanjutnya.

\section{Hasil dan Pembahasan Kegiatan Pendahuluan}

1. Perizinan

Pada tanggal 2 Februari 2020 tim abdimas mengirim surat permohonan dan menelepon kepada mitra tentang pengadaan Penyuluhan Pembuatan Souvenir Untuk meningkatkan keterampilan berwirausaha kepada santriwati di yayasan tahfidzul Qur'an ArRahmani yang beralamat di Jl. Al-Ihsan Rt 02/07 Kp. Sawah, Kec. Ciputat, Kab. Tangerang Selatan.

2. Pendataan para santriwati di Yayasan

Tahfidzul Qur'an Ar-rahmani yang berjumlah 30 santriwati.

3. Setelah mendapat izin dari pihak

mitra, kemudian tim abdimas melakukaan pendataan santriwati untuk menindak lanjuti penyuluhan tentang kewirausahaan melalui penyuluhan keterampilan pembuatan souvenir.

\section{Observasi Lapangan (2-4 Maret 2020)}

1. Pertemuan dengan Ketua Yayasan Tahfidzul Qur'an Bapak Ustad Assad

Kegiatan ini kami lakukan untuk menggali data dan informasi tentang santriwati dalam kemampuan mengetahui tentang kewirausahaan.

2. Analisi Permasalahan Mitra

Dari hasil temuan data dan informasi, dihasilkan kendala atau masalah dalam hal keterampilan dan penguasaan tentang kewirausahaan melalui keterampilan membuat souvenir kepada santriwati, sebagai berikut: 
27 | Lies Sunarmintyastuti, dkk : Penyuluhan kewirausahaan...

Kurangnya pengetahuan dan pemahaman santriwati baik di Yayasan Tahfidzul Qur'an tentang kewirausahaan, khususnya pengetahuan kewirausahaan, baik itu materi pembelajaran tu sendiri dan bagaimana cara mendayah gunakan barang-barang bekas untuk membuat suatu souvenir.

1. Penyusunan Materi Penyuluhan

a. Memberikan pengetahuan awal dasar tentang pengertian berwirausaha.

b. Memberikan contoh penggunaan barang-barang bekas untuk kewirausahaan.

c. Memberikan contoh kewirausahaan souvenir produk yang belum jadi dan sudah jadi.

d. Memberikan modul dan menjelaskan proses dan langkahlangkah dalam berwirausaha.

e. Melakukan penyuluhan proses penggunaan media barang-barang bekas seperti: koran/kertas yang bisa dijadikan produk souvenir.

2. Realisasi Kegiatan Abdimas (6 Maret 2020)

a. Pemberian Materi

Tim pengabdian masyarakat memberikan materi tentang kewirausahaan melalui keterampilan membuat souvenir sebagai media keterampilan kewirausahaan berbasis kemandirian dengan tujuan memberikan pengetahuan bahwa inovasi ide kreatif diperlukan dalam menghasilkan suatu souvenir yang baik.

Tim memberikan modul bagaimana pengertian dasar kewirausahaan lalu bagaimana pemasaran menggunakan media sosial khususnya facebook dan instagram, cara penguasaan dan penggunaan media sosial.

b. Penyuluhan kewirausahaan menggunakan media barang-barang bekas, agar santriwati menjadi paham dan mencoba

mempraktekannya dengan membuat souvenir seperti yang diajarkan oleh tim abdimas.

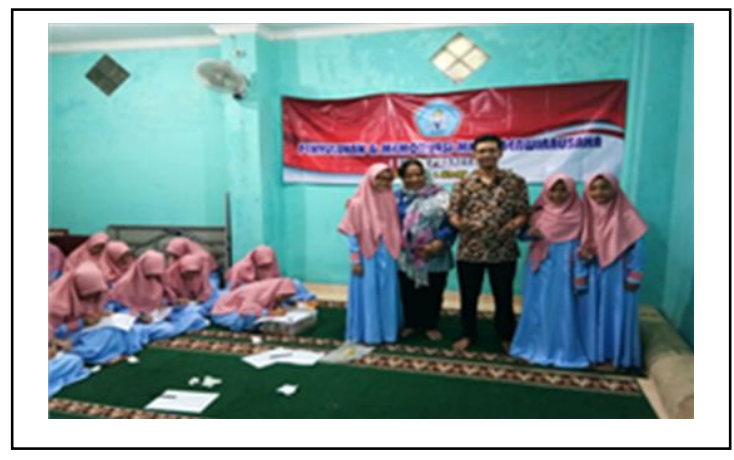

Gambar 1.Siswa sedang mencatat

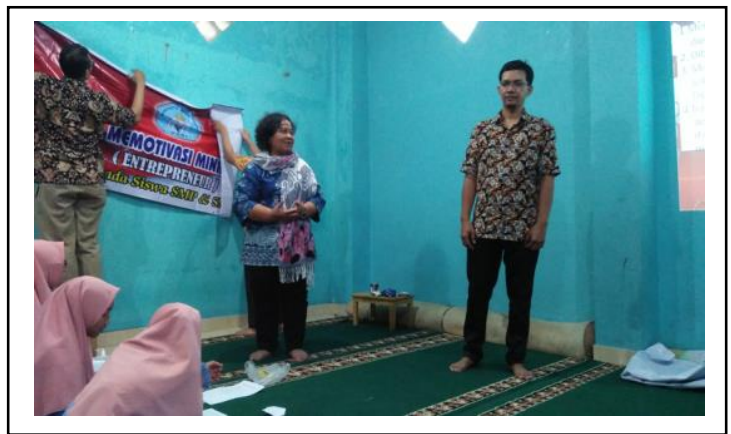

Gambar 2. Proses penyuluhan

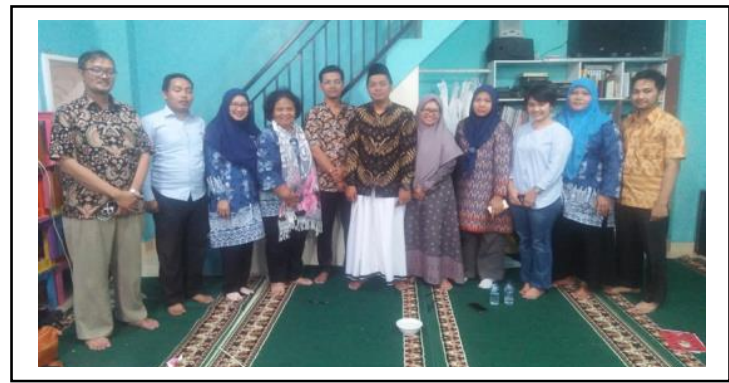

Gambar 3.Bersama yayasan

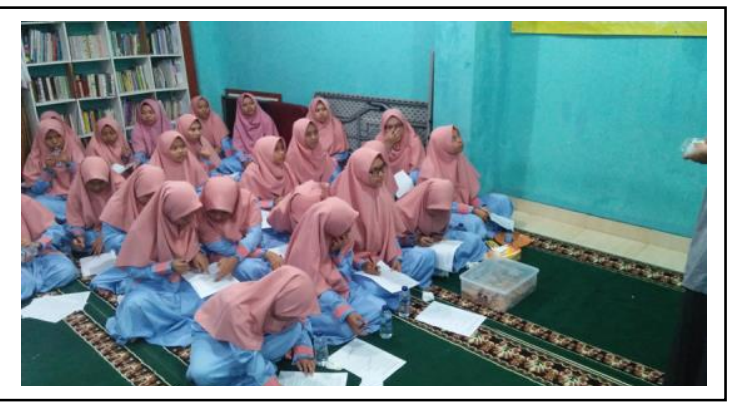

Gambar 4. Siswa sedang menyimak 
Kegiatan penyuluhan dilaksanakan pada tanggal 6 Maret 2020 dengan target peserta penyuluhan mampu mengenal dan mengetahui kewirausahaan melalui pembelajaran materi kewirausahaan membuat souvenir.

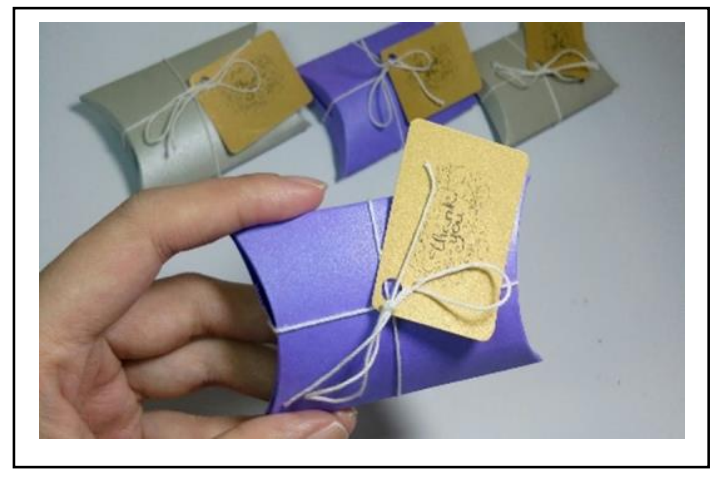

Gambar. 6. Souvenir

Pada proses pembuatan souvenir, para siswi dibagi beberapa kelompok, untuk mempersiapkan berbagai bahan yang disiapkan ,termasuk kertas beka dan alat kerja seperti gunting, lem, pewarna dan sebagainya. Setelah dibagi 3 kelompok, yaitu kelompok,tulip,melati, dan mawar. Adapun produk yang telah dibuat adalah, souvenir, keranjang kecil dan gift bag. Masing - masing diberi trget pembuatan sebanyak 55 produk per kelompok.

Hasil yang dicapai sebagai berikut :

Tabel. 1. Hasil yang dicapai

\begin{tabular}{|l|l|l|l|}
\hline No & $\begin{array}{l}\text { Nama } \\
\text { Kelompok }\end{array}$ & $\begin{array}{l}\text { Produk } \\
\text { yang } \\
\text { dibuat }\end{array}$ & Realisasi \\
\hline 1 & Tulip & Souvenir & $100 \%$ \\
\hline 2 & Melati & Keranjang & $80 \%$ \\
\hline 3 & Mawar & Gift Bag & $70 \%$ \\
\hline
\end{tabular}

Hasil yang telah dibuat dijual melalui koperasi dan pasar. Para siswa menawarkan produk - produk tersebut, kepada masyarakat yang membutuhkan,termasuk kenalan famiili dan lain - lain.

\section{Simpulan}

Kegiatan abdimas yang dilakukan dirasa masih belum sepenuhnya mencapai target dan luaran yang diharapkan, namun kegiatan pengabdian masyarakat ini telah memberikan kontribusi yang positif bagi upaya peningkatan pengetahuan dan kemampuan dalam mengenal dan mengetahui kewirausahaan melalui pembelajaran materi kewirausahaan dan keterampilan dalam membuat souvenir dari barang-barang bekas. Kegiatan ini telah berjalan dengan baik dan dapat disimpulkan sebagai berikut:

1. Para peserta khususnya santriwati di Yayasan Tahfidzul Qur'an Ar-Rahmani antusias dalam kegiatan ini dan mulai timbul ketertarikan dalam mempelajari kewirausahaan.

2. Para peserta khususnya santriwati di Yayasan Tahfidzul Qur'an Ar-Rahmani mampu memahami apa itu makna belajar kewirausahan dan mampu membuat produk serta menginplementasikan dalam kehidupan sehari-hari sebagai bekal masa depan mereka. Hasil produk akan menjadi wujud nyata dari kegiatan pengabdian kepada masyarakat

\section{Daftar Pustaka}

Adi, S., Puspita, F., Ati, A. P., \& Widiyarto, S.(2020). Penyuluhan Dan Pembelajaran Karakter Melalui Pelaksanaan Idul Adha Pada Siswa Sma. Jurnal Pemberdayaan: Publikasi Hasil Pengabdian Kepada Masyarakat, 4(2), 205-210.

Rachbini, D.J. (2001). Pengembangan Ekonomi \& Sumber Daya Manusi a, Penerbit Grasindo, Jakarta.

Redja Mudyaharjo.(2012).Pengantar Pendidikan. PT. Rajagrafindo persada, Jakarta.

Rosadi, N., \& Widiyarto, S. (2020). Character

Development for Class IX Students through Critical Reading Activities 
29 | Lies Sunarmintyastuti, dkk : Penyuluhan kewirausahaan...

at MTs Nurul Hikmah and Driewanti Middle School Bekasi, West Java. KANGMAS: Karya Ilmiah Pengabdian Masyarakat, 1(1), 8-12.

Sunarmintyastuti, L., \& Suprapto, H. A. (2020).Pengembangan SDM Melalui Minat dan Motivasi Santriwati pada Yayasan Taufidzul Qur'an ArRahmani di Ciputat Tangerang Selatan. JURNAL ILMIAH WAHANA PENDIDIKAN, 6(2), 104-109.

Suprapto, H. A. (2018). Pelatihan Pembuatan Proposal Rencana Bisnis zz(Business Plan) Bagi Siswa Madrasah Tsanawiyah Nurul Hikmah Dan Smp Al-Ihsan Guna Meningkatkan Kemampuan Berwirausaha. Abdimas Siliwangi, 1(2), 81-88.

Suryana. (2014). Kewirausahaan. PT. Salemba Empat. Jakarta.

Vernia, D. M., Widiyarto, S., Narsih, D., \& Tiwinyanti, L. (2020). Sosialisasi Dan Pembekalan Strategi Pemasaran Produk Olahan Pisang Pada Siswa Pondok. Jurnal Pengabdian UntukMu NegeRI, 4(1), 125-128.

Vernia, Dellia Mila, et al. "Sosialisasi Dan Pembekalan Strategi Pemasaran Produk Olahan Pisang Pada Siswa Pondok." Jurnal Pengabdian UntukMu NegeRI 4.1 (2020): 125128.

Widiyarto, S., Wulansari, L., \& Hasanusi, F. S.(2020). Pelatihan "English Communicative" Guna Mempersiapkan SDM Berkualitas dan "Competitive". Intervensi Komunitas, 1(2), 125-131. 